\title{
Consanguinizar y Afinizar. La domesticación de los animales, las plantas y los humanos en las acciones de desarrollo
}

DOI

http://DX.DOI.ORG/10.11606/ 1678-9857.RA.2021.184486

\section{Gabriela Schiavoni}

Universidad Nacional de Misiones / Posadas, Argentina

Este artículo versa sobre las formas de familiarización entre los pequeños agricultores y las especies comestibles. Las acciones de desarrollo orientadas a la producción de alimentos intervienen controlando la propagación de animales y plantas y la replicación de relaciones entre los humanos. Nuestro artículo describe las transformaciones del flujo de consanguinidad entre los humanos y las especies alimenticias, a través de la diferenciación de líneas, codificadas por el género, que plantean una oposición entre los sexos. La relación de contrapartes solicitada por los colectivos de desarrollo (cooperativas, asociaciones) suspende la consanguinización de las alianzas y los vínculos políticos y económicos se abren paso a través de los lazos de afinidad.

La investigación etnográfica que sustenta esta contribución se llevó a cabo entre los pequeños agricultores del nordeste de Misiones (Argentina), las Ongs y los programas estatales que incentivan la producción de alimentos en las últimas décadas del siglo XX.

Consanguinity and affinity. The domestication of animals, humans and plants in development actions

ABSTRACT The following article focuses on the different ways of familiarization between peasants and edible species. Development politics pointed towards food production keep vegetal and animal propagation under control, while encouraging the replication of human relationships. The consanguinity flux that links humans and edible species then gets segmented in genre-codified lines, which involve sex opposition. Thus, the kind of partnership requested by the development programs (cooperatives, associations) puts a halt to the "consanguinization" of affines, fostering political and economic relationships, expressed in alliance bonding. instead. The ethnographic research that supports this article was carried out among peasants, and NCO and government agents that have stimulated local food-production in the last decades of the 2oth century, in northeastern Misiones, in Argentina.

Parentesco, domesticación, híbridos, modernidad, reproducción 


\section{INTRODUCCIÓN}

Nuestro trabajo pone en juego una dicotomía clásica de la disciplina: la oposición entre consanguinidad y afinidad, fuertemente arraigada en el dualismo naturaleza-cultura (Viveiros de Castro, 2008). La utilizamos aquí para describir los efectos sobre los humanos, los animales y las plantas derivados de la introducción de semillas y gallinas seleccionadas, en el marco de acciones de desarrollo orientadas a modernizar la producción de alimentos de los pequeños productores de la provincia de Misiones (nordeste de Argentina).

Los datos que presentamos provienen del trabajo de campo etnográfico realizado a lo largo de los últimos diez años en varias localidades rurales del frente pionero del nordeste provincial, conformadas por los procesos de ocupación domésticos de tierras inexplotadas, llevados a cabo una vez concluido el poblamiento dirigido o la colonización.

Siguiendo un modelo abierto de instalación agrícola o frontera agraria, la población campesina no indígena que analizamos se desplazó a lo largo de tres décadas, dando origen a nuevas colonias o parajes rurales. Diversas formas de uniones próximas otorgaron cohesión al conjunto de grupos domésticos involucrados en el poblamiento, constituyendo una parentela.

El núcleo de familias en el que se centra nuestra etnografía establece una primera localización en 1986. Las familias que lo componen provienen de colonias agrícolas más antiguas de Misiones y de los estados del sur de Brasil. El acceso a la tierra, de origen fiscal y luego privado, se efectuó por ocupación directa o a través de mecanismos informales, paralelos al mercado y al Estado, como la compra de mejoras.'

Los cincuenta lotes que componen esta localización inicial son mayoritariamente unidades pequeñas (el 60\% está compuesto por parcelas de 5 a 10 hectáreas de superficie total), dedicadas a cultivos de subsistencia (el 90\% de los lotes produce maíz,

1 | Comercialización informal de lotes agrícolas que toma en consideración el trabajo sobre la tierra (desmonte, siembras, construcciones) realizado por el poseedor. mandioca y poroto). Un 40\% de las unidades registra la presencia de cultivo de tabaco. La autoproducción de alimentos constituye la base de la reproducción social de estos agricultores, cuyo vínculo con el mercado descansa en la agricultura bajo contrato del tabaco, y, sólo en los casos de mayor capitalización, incluye también la yerba mate.

A medida que los hogares se desarrollan, los hijos expanden el poblamiento ocupando parcelas en las proximidades. La alianza opera como un principio de cohesión, pero la importancia del matrimonio no radica en instituir relaciones nuevas sino en estabilizar los lazos existentes. El matrimonio entre pares de hermanos y la reanudación de alianzas con los consanguíneos de los afines constituyen figuras recurrentes (Schiavoni, 2005).

Las prácticas matrimoniales manifiestan una aptitud preferencial de los ocupantes del frente pionero a combinarse entre sí, más que a entrar en vinculación con externos. A diferencia de otros contextos campesinos, la alianza no es objeto de cálculo y estrategia (Bourdieu, 2002; Woortmann, 1995). 
Consanguinidad y afinidad se despliegan como principios complementarios, dando como resultado un agrupamiento multicéntrico, en el que las personas quedan ligadas por lazos derivados de la superposición de consanguinidad y alianza, restando nitidez a la conexión unilineal y favoreciendo la indistinción de los parientes políticos.

También la propagación de las plantas y animales alimenticios, para autoconsumo (la producción "para el gasto") se lleva a cabo a través de combinaciones que estabilizan lo diverso, duplicando lo próximo ("lo que está en la casa"). La domesticación casera multiplica especímenes por proximidad, a partir de un germoplasma que circula en la red de conocimiento mutuo, dando origen a una agricultura autogenerativa o endoagricultura de los alimentos familiares. Así, cuando indagamos acerca de los modos de obtención de las mudas de mandioca, los agricultores invariablemente responden: "es lo que está en casa"; "es rama, se guarda", "siempre hay", "ya se tiene".

El carácter casero o criollo de las etnovariedades o landraces emana de esta forma de propagación no planificada, sin correspondencia estricta con un conjunto determinado de rasgos fenotípicos. Son "semillas hechas"; "conocidas"; "vienen de los abuelos, de la generación de antes"; "se pueden guardar".

Las críticas dirigidas a la lógica clasificatoria del totemismo, en razón del carácter abstracto que asigna a las relaciones entre los humanos y las entidades naturales que les sirven de éponimos, abrieron la posibilidad de un tratamiento alternativo de dichos vínculos. Hiatt (1969), por ejemplo, afirma que las especies naturales y los seres humanos pueden asociarse en virtud de su proveniencia de un mismo paisaje o lugar, quedando ligados por un lazo que no sería lógico sino de contigüidad.

En el caso que nos ocupa, humanos y no humanos comparten un formato de propagación no selectivo, basado en la proximidad física, sin engendrar grupos estabilizados que se perpetúan al modo idéntico.

Un lazo general de este tipo organiza la multiplicación de los humanos, y de los vegetales y animales alimenticios, en la pequeña agricultura de las localidades de la frontera agraria que describimos aquí. En efecto, así como las etnovariedades surgen de las asociaciones que ocurren en el espacio próximo, también la elección del cónyuge se lleva a cabo al interior de la red de conocimiento mutuo, entre familias vecinas, unidas por lazos pre-existentes.

La concordancia entre las clasificaciones de los humanos y las de la naturaleza responde, de acuerdo a Chaumeil y Chaumeil (1992), a la existencia de una taxonomía general de lo viviente, basada en la identificación de distintos umbrales de alteridad: consanguíneos, afines y extranjeros.

En el caso que analizamos, las acciones de desarrollo segmentan el primer umbral o flujo analógico de asociación por contigüidad, creando alteridad al instituir modos de multiplicación basados en la selección.

La promiscuidad del rozado familiar, en el que las variedades crecen asociadas, es ordenada mediante acciones de distanciamiento: separación de plantíos con 
clases de maíz diferenciadas y segregación de las gallinas provistas por el proyecto de desarrollo.

Los objetos técnicos puestos en circulación por las agencias corresponden a la noción clásica de domesticación, es decir, la imposición de un diseño humano sobre una naturaleza inerte. Semillas y gallinas mejoradas, así como las formas de sociabilidad adosadas a ellas (grupos de mujeres, cooperativas y sindicatos), interrumpen el vínculo de continuidad que caracteriza la propagación de los humanos y las plantas en la sociedad local. El intercambio no mediado, basado en la proximidad, existe ahora en fricción con los nuevos esquemas de relacionamiento, que otorgan visibilidad creciente a los vínculos de los que depende la reproducción.

En la constitución de un orden, el pragmatismo identifica dos modos de neutralización de la fragmentación, inspirados en el tratamiento de la naturaleza: el modo político y el modo analógico (Boltanski, 2009). En el primer caso, se definen tipos ideales, fundados en calificaciones generales, que duplican los existentes en base a esencias que la apariencia de las cosas tiende a traicionar. En el segundo, se parte de las singularidades y se busca insertarlas en una red, considerando los parecidos derivados de propiedades sensibles (color, olor, forma, posición). A diferencia del proceder político, el modo analógico no contempla una subida de generalidad, enunciable en un principio externo de cohesión, de manera que las entidades asociadas mantienen su diversidad. ${ }^{2}$

La endoagricultura de los alimentos familiares, así como la red de lazos de la parentela local, estabilizan la diversidad, procediendo de manera analógica. La coherencia del conjunto se desprende de asociaciones de lugar, fruto de la proximidad, sin correspondencia con un criterio explícito.

El modo de propagación casero constituye un nivel no verbal de emergencia de relaciones fundamentales del grupo. Las asociaciones no son enunciadas, ni descriptas a partir de un conjunto de atributos, sino que actúan asemejando lo próximo.

Los objetos técnicos del desarrollo, a su vez, derivan su homogeneidad de inscripciones tecnocientíficas, que estabilizan lo diverso a partir de un principio externo o calificación. Este modo de tratamiento duplica los existentes, suprimiendo las interacciones con las dinámicas ambientales locales. El control desarraigado de la descendencia deviene un rasgo propio de las acciones de modernización agraria, perceptible en la afirmación de una agricultora entrevistada cuando califica los beneficios del desarrollo, señalando que: "los proyectos te dan raza".

La normatización vegetal se impuso tempranamente en la región. Las plantaciones de yerba mate de principios del siglo $X X$ admitieron una única especie, la llex paraguariensis, multiplicada a partir de mudas provenientes de viveros registrados, abastecidos actualmente por el banco de germoplasma del Instituto Nacional de Tecnología Agropecuaria.
2 | Racine (1989) y también Descola (2012) recuperan el interés en la analogía, no solo como procedimiento heurístico, sino como modo de constitución de lo real. A diferencia del estructuralismo, que enfatiza los contrastes $y$ el primado de las relaciones, el modo analógico destaca las similitudes, el principio de identificación y las conexiones contenidas en los propios términos. 
Del mismo modo, las exigencias sanitarias de la producción comercial de citrus impulsaron el empleo de injertos certificados, engendrados por las tecnociencias, que desplazaron a los híbridos caseros, cuya eficacia radicaba en la familiaridad. Como relata un productor: "[en los injertos caseros] vos injertás plantas que están en producción, que sabés que dan. En cambio con esas plantas del invernáculo, vos no conocés la planta".

Estas prácticas, de larga data en los cultivos de renta, representan una dinámica reciente en la producción de alimentos en Misiones, de manera que nuestro artículo se orienta a captar esta transición. Las dos formas de estabilización que venimos reseñando se mantienen en fricción, y el proceso resultante constituye un precipitado de ambas. En efecto, la propagación de plantas y humanos, en base a la proximidad y a la semejanza, contrasta con la reproducción de equivalentes abstractos, calificados según un principio externo, tales como 'semillas seleccionadas', 'mujeres rurales' o 'socios de cooperativas'. Nuestro razonamiento, sin embargo, no apunta a establecer una dicotomía entre estas dos formas de acción, sino que se encamina a detectar la matriz de relaciones más amplia, que engloba lo institucional (externo y segmentado), transformándolo en casero (continuo e implícito), de acuerdo a un proceso de individuación por familiarización.

En efecto, la refamiliarización subvierte la operación de segmentación promovida por el desarrollo, poniendo en circulación los insumos tecnocientíficos a través del lazo madre-hija, en el marco de colectivos fundados en un englobamiento filial. Del mismo modo, la cooperativa de comercialización de semillas se perpetúa como una casa, mediante las alianzas matrimoniales entre las familias vinculadas a la ONG. Es decir, no se trata de un parentesco ya hecho que presta su formato a la institucionalidad del desarrollo, sino que ésta deviene una dimensión más de las dinámicas familiares, que, a su vez, experimentan una pérdida de fluidez, expresada en la consolidación de líneas de descendencia que segmentan el formato multicéntrico de la sociedad local.

\section{ANALOCÍA Y GENEALOGÍA: EL PAPEL DE LOS OBJETOS}

\section{TÉCNICOS EN LA CONSTITUCIÓN DE AGREGADOS}

La noción de casa supone una mirada menos determinista sobre el parentesco. Al incluir la dimensión histórica y el papel de los objetos en la conformación de los agregados, permite comprender las relaciones entre los sentidos material y moral que, de acuerdo a Benveniste (1994), coexisten en la etimología de la palabra casa.

Revisando el alcance de la institución de casa, Lévi-Strauss establece un contraste entre las sociedades melanesias y las africanas, con respecto a la estructura y al reclutamiento de los grupos: "Analógica en un caso [Melanesia], la estructura sería 
genealógica en el otro [África]; y el reclutamiento sería aquí por la descendencia y allá por la filiación (Lévi-Strauss, 1984: 201). La noción de casa incluye fórmulas híbridas: mezcla de cognatismo y agnatismo. Se trata de sociedades que enfrentan el problema de la integración de un linaje agnático y de una parentela cognática, de modo que tienen que establecer mecanismos para poner a distancia una parte de la parentela, que sino se extendería indefinidamente a lo largo de las generaciones, ahogando a los agnados.

Y continúa Lévi-Strauss: "En vez de poner la consanguinidad de un lado y la alianza y el intercambio en el otro, como ocurre en la mayoría de las sociedades en las que se forjó la teoría antropológica, Nueva Guinea desplaza la línea de demarcación: distingue dos categorías de parientes: aquellos con los que se intercambia y aquellos con los que se comparte. En lugar que la distinción entre consanguinidad y afinidad sirva para delimitar el dominio del intercambio, es la facultad del intercambio la que sirve para distinguir la parentela en consanguíneos y aliados" (Lévi-Strauss, 1984: 206-207).

Los análisis de Wagner (1977) sobre los daribi, y los de Feil (1978) sobre los enga, son citados por Lévi-Strauss para ejemplificar este dispositivo de extranjerización de próximos, efectuado por el intercambio. De acuerdo a la fórmula de Wagner, mientras la consanguinidad fusiona, el intercambio posee la facultad de segmentar. Entre los enga, la conversión de agnados en no agnados se realiza mediante la instauración de un vínculo de contraparte de intercambio - denominada "enderezar el camino" (Feil, 1978) —, que activa lazos complementarios a los de descendencia, tales como las relaciones matrilaterales y afinales.

En nuestro terreno de estudio, las relaciones de alianza no actúan segmentando la localidad porque la mayoría de los matrimonios se anudan entre próximos. La dos figuras de alianza más frecuentes son el matrimonio doble, entre pares de hermanos (no siempre del mismo sexo), y los re-encadenamientos de alianzas con los parientes políticos (en la misma generación o en generaciones sucesivas).

La expansión doméstica del poblamiento impulsada por la búsqueda de tierra, en un contexto de gestión limitada del Estado, entrelaza las preferencias matrimoniales y los nuevos emplazamientos.

La relativa fluidez de la oferta de tierra, fruto de la situación de frontera agraria de la fracción Nordeste del territorio provincial, pone en juego un formato de reproducción social en el que el padre no es necesariamente quien provee la parcela. Crupos de hermanos y cuñados, y a veces yernos y suegros, se desplazan hacia extensiones menos pobladas de las proximidades con el fin de obtener chacras, a través de los mecanismos informales ya mencionados (ocupación directa o compra-venta de mejoras). Las figuras endogámicas de la alianza retroalimentan las coaliciones domésticas horizontales de la ocupación agrícola no planificada.

Así, en uno de los apéndices poblacionales de nuestro sitio inicial, registramos el caso de dos hermanas, Sonia y Adriana. Sonia conoció a su marido en una fiesta 
de doma en el Km. 304, colonia vecina, y antes se habían visto en el colectivo. Poco tiempo de novios y se instalaron en el nuevo asentamiento: "Mi familia venía a visitarme. Acá era feo. No había nada. Ni me di cuenta y mi hermana ya estaba con Rosi [hermano de su marido que reside en el mismo lugar]. Vinimos un día y encontramos que ellos se habían acompañado". Posteriormente, una tía de ellas, se acompañó con el hermano mayor de sus cónyuges, que permaneció en la localización anterior (trabajo de campo, 2015).

En otro caso, la familia habita el asentamiento original. Se trata de un reconocido plantador de tabaco que tiene cinco hijos varones. El padre apoyó la instalación agrícola del hijo mayor, en un paraje contiguo a la explotación paterna, y los demás hijos fueron accediendo a las parcelas a través de vinculaciones entre vecinos (información sobre lotes desocupados y condiciones de acceso). Camila, la mujer de uno de los hijos menores, originaria de una colonia vecina, es hermana de la esposa de uno de los hermanos mayores del marido. Relata la duplicación de alianzas en términos jocosos: "Mi hermana arregló un matrimonio para mí" (trabajo de campo 2015).

Asimismo, las familias que estaban ubicadas próximas en los sucesivos lugares en los que habitó el grupo constituyen una fuente de provisión de cónyuges, de manera que los antiguos vecinos son re-unidos mediante una alianza. La madre de un joven agricultor recuerda: "Mi hijo y la mujer se conocieron en el velorio de la mamá del vecino. Más bien: se re-conocieron. Porque nosotros ya éramos vecinos de la familia de ella en la colonia en la que vivíamos antes" (trabajo de campo, 2013).

Las combinaciones matrimoniales, anudadas al interior de la red de conocimiento mutuo fundada en el lugar, modelan la totalidad de las uniones, configurando una trama continua que incluye a la mayoría de las familias. Las alianzas concertadas al exterior de este conjunto revisten un carácter excepcional; la fluidez de los vínculos califica las transacciones locales.

Indagando acerca de la existencia de un documento escrito relacionado con el préstamo de una parcela de tierra, uno de los agricultores afirma: "No hay contrato porque somos cuñados". Del mismo modo, yernos y suegros operan frecuentemente como asociados para migrar y ocupar nuevas tierras. Es decir, los vínculos de alianza concertados en el lugar son consanguinizados y la consanguinidad es experimentada como continuidad. El cuñado es semejante a un hermano, el suegro a un padre y la nuera a una hija.

Los vegetales y animales alimenticios mantienen lazos de este tipo entre sí y con los humanos. El desarrollo transforma dicho entramado, segmentando la continuidad de los allegados e iniciando un proceso de alineamiento, que dirige la fluidez de la red hacia una dirección determinada.

Las críticas y reformulaciones de la noción de casa (Codelier, 2013; ${ }^{3}$ Carsten y Hugh-Jones, 1995; ${ }^{4}$ ) colocan la discusión más allá, o más acá, de Lévi-Strauss. Sin embargo, el hecho de incluir la participación de los elementos materiales — objetos
3 | En su crítica a la noción de casa, Codelier desarrolla un argumento opuesto al que sostenemos aquí y ataca especialmente la afirmación de Lévi-Strauss acerca de que los viejos lazos de sangre se alteran para dar lugar a determinaciones económicas y políticas. Afirma que: "En ninguna sociedad 'primitiva' las relaciones de parentesco alcanzaron para constituir el armazón de la sociedad.

El armazón de una sociedad consiste en la combinación, cada vez diferente, de dos conjuntos de relaciones sociales: por un lado, relaciones de parentesco; por otro, relaciones político-religiosas" (Godelier, 2013: 208-209).

4 | En su crítica a la noción de casa, Codelier desarrolla un argumento opuesto al que sostenemos aquí y ataca especialmente la afirmación de Lévi-Strauss acerca de que los viejos lazos de sangre se alteran para dar lugar a determinaciones económicas y políticas. Afirma que: "En ninguna sociedad 'primitiva' las relaciones de parentesco alcanzaron para constituir el armazón de la sociedad.

El armazón de una sociedad consiste en la combinación, cada vez diferente, de dos conjuntos de relaciones sociales: por un lado, relaciones de parentesco; por otro, relaciones político-religiosas" (Codelier, 2013: 208-209). 
valiosos, construcciones arquitectónicas, sustancias corporales -, en la constitución del parentesco se mantiene como un aporte significativo para nuestro problema de estudio. En este sentido, la apropiación de los objetos técnicos del desarrollo deviene fuente de exclusividad de algunos grupos domésticos del frente pionero de Misiones, que se perpetúan controlando ventajas económicas a través de los lazos de sangre.

Argumentando que el hijo y el padre no son entre sí suficientemente otros, Aristóteles proponía excluir del derecho político los problemas correspondientes al orden interno de la familia: "Los allegados (...) no son completamente otros. (...) Aparentemente dobles, no son más que uno porque se encuentran en connivencia" (Boltanski, 2000: 263-264).

La relación de contraparte o socio promovida por los colectivos de desarrollo segmenta la proximidad de los allegados. Sin embargo, los participantes no devienen entre sí suficientemente otros, ya que la totalización de tipo político es hibridada por la familiarización. Así, el intento de una socia de conformar por su cuenta una organización de mujeres fue desalentado por las madres patrocinadoras de los grupos basados en el englobamiento filial. La hija rebelde recibió la siguiente advertencia: "Si nosotros formaba un grupo aparte, no podía ser parte del grupo".

La endoagricultura de los alimentos contiene en sí misma una receta de reproducción social. Su carácter autogenerativo y de endogamia implícita queda manifiesto en el registro material de duplicación de lo viviente: propagación por vástagos y semillas propias. La intervención de los humanos consiste en acompañar estos procesos. Se tratan de formas de relación entre las plantas y los humanos en las que se busca favorecer las condiciones del ente domesticado sin ejercer una manipulación directa sobre él (Haudricourt, 1962). Una continuidad de este tipo es mencionada por Lévi-Strauss (1971) a propósito del origen de las plantas cultivadas en los mitos amerindios, cuando afirma que implican a términos contingentes de la constelación doméstica, soslayando la oposición principal entre dadores y tomadores de esposas.

La aptitud preferencial hacia la combinación interna se expresa también en la fusión entre engendrante y engendrado, una operación frecuente en los vegetales alimenticios, documentada en varias etnografías, a veces como un vínculo de maternidad (Racine, 1986; Hatt, 1951), y otras como un lazo entre las distintas partes de una planta (entre la raíz y el tallo o entre el grano y la espiga). ${ }^{5}$ La relación entre el tallo y el brote de una planta cultivada encarna la filiación materna en Indonesia, mientras que los árboles no domesticados de la selva atestiguan acerca de los vínculos agnáticos (Fox, 1977).

En este sentido, la mandioca constituye en la etnografía sudamericana una

$\mathbf{5}$ | Así, en las Trobriand, la raíz de taro de la que brotan plantas secundarias se denomina madre mientras que los brotes son considerados hijos mayores y menores, de acuerdo al orden de aparición. figura privilegiada de la reduplicación de vínculos (Taylor, 2000). Es la expresión de lazos establecidos con un grado mínimo de diferenciación, caracterizados por la indistinción entre los términos y las relaciones.

Etnografías amerindias recientes ponen de manifiesto una relación de identificación entre los humanos y los vegetales, en el marco de las ontologías animistas. 
Consideradas como sujetos vivientes, las plantas cultivadas mantienen con las mujeres un vínculo filial. Los trabajos de Maizza (2014) sobre los jarawara muestran que el crecimiento de las plantas depende de cuidados semejantes a los dispensados a los niños, a través de la mirada. Las mujeres krahô establecen un compañerismo con las batatas que les brindan su prole (Morim de Lima, 2017). Asimismo, el carácter multicéntrico del parentesco humano queda plasmado en la forma circular del plantío de batata. La analogía entre vegetales y humanos también es profundizada por los análisis de Cabral de Oliveira (2008) sobre los wajãpi, entre quienes la intensa búsqueda de diversidad vegetal es correlativa de una apertura hacia el otro, entre los humanos.

En el caso que analizamos, la analogía entre los humanos y los vegetales y animales alimenticios se funda en el modo de propagación, basado en vínculos no selectivos que revelan una tolerancia hacia la fluctuación de los existentes, que no cristalizan en líneas de descendencia, ni se perpetuán de acuerdo a determinados criterios.

La denominación criollo hace referencia a este formato de estabilización y engloba, asimismo, los especímenes engendrados a contrapelo de los procesos de domesticación planificados. De este modo, aún cuando las empresas de tabaco prohíben la conservación de las semillas, los agricultores las guardan y multiplican plantas, generando variedades que llaman criollas. La práctica es descripta por un campesino del lugar en los siguientes términos: "Una de las exigencias del [cultivo] tabaco, es la semilla. Ya no quiere que use más K y 9D, que le llaman criollo. La gente sigue usando porque rinde más en kilos".

Los híbridos entregados anualmente por las empresas están diseñados para satisfacer los requerimientos cambiantes del mercado, de modo que la conservación de semillas por parte de los productores va a contrapelo de la lógica institucionalizada del cultivo. La asociación de plantadores de tabaco alerta sobre este riesgo:

La Comisión Técnica de Tabaco de la Provincia realizó diversos controles con el objetivo de detectar plantaciones provenientes de semillas no recomendadas (...) Estas variedades de semilla fuera de tipo, comúnmente llamadas K y 9D o caseras, tienen un extraordinario rendimiento a campo, que a primera vista resultaría un gran beneficio para el productor. Pero debido principalmente a sus prominentes venas y tallos la cantidad de tabaco utilizable por los compradores disminuye considerablemente (Asociación de Plantadores de Tabaco de Misiones, 1999).

En relación a esto, una de las agricultoras de nuestra localidad de estudio relata:

Estamos plantando tabaco criollo, o sea [tabaco] Burley con semillas hechas por nosotros. Eso te da más peso. Papá discutió conmigo porque quiere que haga sólo el Burley que te da la empresa. Pero mis tíos me dijeron que le meta con el criollo. Las empresas quieren sólo lámina [hoja] y no tallo, y a nosotros nos conviene el tallo porque es lo que pesa (trabajo de campo, 2015). 
Esta refamiliarización de la domesticación institucional, puesta de manifiesto aquí a propósito de un cultivo industrial, será materia de los últimos apartados de este artículo, en los que se relatan procesos semejantes, llevados a cabo en conexión con especies alimenticias.

\section{CLONES Y LIGNÉES: ESTRATEGIAS DE ESTABILIZACIÓN DE LA DIVERSIDAD}

Haudricourt (1964) establece un contraste, que luego contribuye a relativizar, entre la organización clánica y la multiplicación por vástagos por un lado, y la agricultura de semillas, con líneas de descendencia (lignées), por el otro. En el primer caso, la continuidad está dada por la repetición de un mismo individuo, mientras que en el segundo, la filiación sigue meandros que recuperan diversas vertientes: en cada estación se obtienen individuos diferentes, el clima o el suelo favorece a unos a expensas de otros, pueden producirse hibridaciones con los parientes salvajes de la planta cultivada, etc.

Al incorporar la agricultura de semillas (cereales anuales como el maíz o el arroz), los cultivadores de tubérculos reducen la diversidad, aporcando las plantas y replantando mudas seleccionadas. A su vez, la diversidad que, no obstante, exhibe la agricultura de vástagos, tiene su origen en los espacios "asilvestrados" de los terrenos en barbecho. La extracción de tubérculos nunca es completa y los retoños que permanecen florecen y producen variedades nuevas. Esta capacidad generativa de los espacios silvestres tiene su correlato en la reproducción social: así como el origen de un nuevo clon se remonta a una planta proveniente de terrenos silvestres, el origen de un nuevo clan se remonta a un extranjero que se incorpora.

Es decir, la base biológica fija de la agricultura de vástagos es ampliada mediante especímenes provenientes de los espacios asilvestrados. A su vez, la selección realizada por los propios agricultores limita la diversidad de individuos de las múltiples descendencias o lignées de la agricultura de semillas. La estabilización de la diversidad contempla simultáneamente la producción de extranjeros y el alineamiento de lo semejante, aunando la lógica sustractiva del seleccionador a la lógica aditiva del coleccionista.

El privilegio acordado a las semillas por parte del Estado explota la mayor capacidad de centralización de este modo de reproducción (Meillassoux, 1978), así como el margen más amplio de maniobra que adjudica a los humanos en el diseño de lo viviente.

Sin embargo, el registro etnográfico documenta una variedad de formas de manipulación, que no se agotan en el contraste entre la replicabilidad de los vástagos y la diversidad de la agricultura de semillas.

Lévi-Strauss destaca la extrema pureza de las semillas en las sociedades indígenas, en las que prima el terror a la circulación: una semilla trasplantada puede arrastrar el espíritu de la planta que desaparecerá de su lugar de origen, afirman en 
Guatemala a propósito del maíz. Así: "Es posible intercambiar mujeres y al mismo tiempo negarse a intercambiar semillas" (Lévi-Strauss, 1963: 146).

En Melanesia, agrega el autor, la exogamia mínima de líneas de descendencia y aldeas es compensada por una endoagricultura exacerbada de vástagos. Así, en Dobu, Nueva Guinea, marido y mujer provienen de líneas diferentes y cada uno aporta sus ñames que cultiva en huertos separados.

En la región amazónica, Emperaire señala que la reproducción por esquejes, al garantizar la continuidad de los individuos, facilita el establecimiento de una cadena de filiación. Las mandiocas con nombre son las multiplicadas de este modo, que producen pies idénticos. En efecto: "la multiplicación por semillas ${ }^{6}$ al no permitir el control de la descendencia, desactiva la cadena de filiación de la mandioca. De ahí la denominación de mandioca sin padre, sin madre, sin nombre o también mandioca encontrada o semilla" (Emperaire, 2010: 85).

Rival (2001), a propósito de los makushi de Guyana, subraya la capacidad creativa de la reproducción por vástagos (mantienen 76 variedades de mandioca amarga; Manihot esculenta Crantzssp. esculenta, Euphorbiaceae), mientras que la propagación por semillas es vista como menos maleable.

En nuestra zona de estudio, el naturalista suizo Bertoni, que estudió los cultivos de Misiones y Paraguay a fines del siglo XIX, alertó acerca de los riesgos que entrañaba la reproducción de la mandioca a partir de semillas, dado que no existe una separación completa entre los grupos de variedades tóxicas y mansas (Bertoni, 1900: 210). En su tratado sobre la mandioca, aconsejó: "La prudencia debe ser mayor si las plantas han sido obtenidas de semilla; aunque esta venga de una variedad absolutamente mansa e inocua, es muy fácil que produzca plantas bravas mezcladas con las mansas" (Bertoni, 1900: 217-18). La reproducción por esquejes, en cambio, ordena la indiferenciación y permite controlar la descendencia.

Este último modo de propagación, sin embargo, fue considerado negativo por el enviado del Ministerio de Agricultura de la nación argentina que, unos años más tarde, recorrió el territorio de Misiones. Señaló: "No conozco casos de reproducción por semilla, que es el indicado para obtener nuevas variedades; variedades que convendría formar - persiguiendo el objetivo de mayor rendimiento en fécula con destino a la industria" (Yssouribehere, 1904: 140).

En la endoagricultura de Gabón (África occidental), descrita por Delêtre y otros (2011), la propagación por vástagos está en la base de las estrategias de control de los clones y de los grupos humanos. Dado que la mandioca constituye un cultivo eminentemente femenino, la difusión de variedades se halla conectada con los intercambios matrimoniales y con las reglas de descendencia, dando lugar a dos modos principales de circulación del germoplasma.

En la transmisión afinal, característica de los grupos patrilineales y virilocales del Norte, las mudas son provistas exclusivamente por la suegra, evitando que las

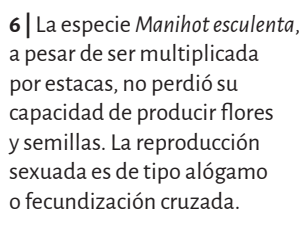


mujeres aporten clones extraños. A su vez, la transmisión vertical, frecuente en los grupos con matrimonios menos controlados, ya sean de descendencia matrilineal o patrilineal, incorpora también los clones aportados por las esposas.

Mientras que la primera forma de transmisión comprende sólo tres variedades de mandioca, la segunda pone en juego unas sesenta clases. Los autores agregan que es probable que la gran diversidad de variedades de mandiocas observada en las sociedades amerindias esté asociada a la difusión de estructuras cognáticas, en las que los clones se transmiten tanto de madre a hija como de suegra a nuera (Delêtre y otros, 2011: 18253).

El repertorio estrecho de variedades que conforman la endoagricultura de los alimentos que estudiamos aquí no es el resultado de la restricción en la transmisión de simientes, sino de un modo de propagación que conlleva un desinterés por el control de la descendencia con el propósito de obtener tipos estables.

El acceso a las mudas y semillas se efectúa sin la mediación de dinero, en el marco de redes de conocimiento mutuo. Ese formato, de larga data en la agricultura familiar de Misiones, está documentado en las memorias de los colonos, agricultores inmigrantes de ultramar, que se asentaron en la provincia a principios del siglo XX?

En nuestra localidad de estudio, cada hogar dispone de hasta tres clases de mandioca y otras tantas de maíz, poroto, zapallo y batata. Difundidas sin restricciones, las plantas del autoconsumo son identificadas mediante denominaciones laxas, que subestiman las diferencias, y están referidas a atributos generales, comunes a varios tipos, tales como el color, el tamaño o la forma.

Indagando acerca de las mandiocas que cultiva, una de las agricultoras de nuestra localidad de estudio, responde en estos términos: "Se planta la amarilla, la cáscara rosa y la comercial". Cuando preguntamos si la comercial es la mandioca para almidón, responde: "No, la comercial blanca, que cocina todo el año, la de hojita verde".

Otra agricultora refiere: "Mi hijo me trajo rama en la camioneta. Mandioca cáscara rosada que cocina rápido, le dicen 'pronta mesa'. La negra que tengo demora mucho".

En otro caso, el relato acerca de las variedades cultivadas comprende la siguiente enumeración: "Tengo dos clases, una que está cerca del rozado de tabaco, que ya tiene dos años. No cocina bien. La otra es la cáscara rosa, de hojita ancha. Esa cocina todo el año. Las mudas me dió mi tío, de Fortaleza".

Un estudio reciente (Stampella, 2015) menciona el empleo de cuatro variedades de mandioca en la población rural de Misiones ("pomberita", "horquetuda", "blanca", "común").

El ya mencionado naturalista Bertoni, a fines del siglo XIX, había catalogado veintidós clases de mandioca en Paraguay y reconocido ocho en Misiones, señalando que las clases más difundidas eran tres: 'concepción', karapé y mandiyu. Los nombres guaraníes de dos de estas variedades aluden al color de las raíces y a la estatura de la planta, evidenciando además la proveniencia indígena. Con respecto a la variedad
$7 \mid$ Un colono de origen suizo ofrece un relato sobre la obtención de semillas en el momento de su arribo a Misiones, en 1937. Dice así: "Visité a un vecino de habla alemana a más o menos $6 \mathrm{~km}$ de distancia para comprarle diversas semillas (...) Hacia la noche volvía a casa con semillas de toda clase sin haber pagado por ellas ni un centavo. Este buen chacarero daba por sobreentendido que debía ayudar a un principiante (Gallero, 2008: 89). También, en otro caso, la hija de un inmigrante refiere: "Mamá sembró verduras (...) las semillas las había traído de Suiza y [acá] la señora Scheifler nos dio de cebollas, ajos y de unos repollos que hacen clones (...)También plantamos maíz, mandioca, porotos y tabaco. Las ramas y semillas las conseguíamos de las familias de alemánbrasileros (Gallero, 2008: 167). 
'concepción', Bertoni relata que fue introducida, desde Brasil, por la esposa de un ganadero del departamento Concepción (Paraguay), a principios del siglo XX. Esta mandioca, señala, es "una de las peores que existen (...) va desalojando a las buenas, por la única ventaja de ser muy productiva en los terrenos pobres, y con poco trabajo, lo que conviene a los que plantan para el abastecimiento de las ciudades". Y continúa: "A fines del siglo pasado, era desconocida en el Paraguay; en cambio era muy conocida en el Brasil, donde los fazendeiros la cultivaban en grande escala para la alimentación de los esclavos (...) allá la llaman "Mata hambre”, porque para tal cosa sólo sirve (Bertoni, 1927: 104).

A mediados de la década de 1960, Martínez Crovetto (1968) registra seis variedades de mandioca cultivadas por los grupos guaraníes de Misiones, identificadas por la altura, el color, la forma de los tubérculos o el lugar de proveniencia (karapé, morotí o blanca, puku o larga, pombero, konché, yerutí). Unas décadas más tarde, Pochettino (2007) identifica sólo dos clases de mandioca en las comunidades misioneras del valle del Cuñapirú (negra y blanca).

En las ferias de pequeños productores de Misiones, observamos siete variedades de mandioca, sin que la identificación de clases constituya un atributo decisivo en el momento de la comercialización. ${ }^{8}$

La gran diversidad que exhiben las plantas cultivadas en las sociedades tradicionales es tributaria de formas de sociabilidad y de procesos de conocimiento característicos (Carneiro da Cunha, 2012). La complejidad de estas prácticas es sustituida gradualmente por esquemas más afines a la lógica del Estado y las tecnociencias.

Así, el catálogo de tecnologías para pequeños productores de la agencia gubernamental de agricultura de la Argentina (SAGyPA-Proinder, 2004) señala como una dificultad el hecho que "tradicionalmente los pequeños productores guardan su propia rama semilla de un año para otro y cultivan mandioca a través de la siembra de materiales propios o intercambiados con productores vecinos". El catálogo propone, entonces, la introducción de clones para consumo familiar, provenientes del banco de germoplasma del INTA (Instituto Nacional de Tecnología Agropecuaria) de la provincia de Formosa. ${ }^{9}$

A su vez, el INTA de la provincia de Misiones (INTA, 2008) identifica los cultivares de mandioca de la región, distinguiendo los de consumo y otros con destino industrial. Entre los ocho pertenecientes a la primera categoría, se incluyen dos variedades indígenas. Los destinados a la industria se superponen a los de consumo, registrando dos de uso industrial exclusivo. Finalmente, la Biofábrica S.A., una empresa con participación del Estado, que investiga y comercializa material de reproducción en Misiones, ofrece siete variedades aptas tanto para la industria como para la venta en fresco.

Las operaciones de protección de la diversidad de las especies alimenticias en nuestra zona de estudio se tradujo en acciones tendientes a fomentar el intercambio
8 | "No sabía que la mandioca tenía clase. Es mandioca, no más!", fue la exclamación que escuchamos en una feria de la ciudad de Posadas, en ocasión de nuestra indagación acerca de las variedades comercializadas.

9| Las variedades recomendadas son Corrientes 74, Rocha, Caoba, Concepción, Blanca Caá Guazú, Cerro Azul EE25/1, Verde Olivo, entre otras, destacándose el clon Corrientes 74 . 
entre los agricultores a través de ferias de semillas nativas. El efecto paradojal de esta medida fue "la persistente pérdida de variedades" (INDES, 2008). Según relata un técnico involucrado en estas acciones: "Con las ferias de la semilla lo que se vio es que se iban perdiendo las variedades, por el intercambio entre las familias. De arroz había 16 variedades. En la última feria de semilla sólo había dos variedades, bajó a dos".

La generalización del intercambio de semillas se plantea en contraposición al control de la diversidad efectuado por la agricultura y la cría científicas, en las que la restricción de la circulación y la planificación de las cruzas desempeñan un papel clave. En su libro sobre la domesticación, Digard (2009) relata el surgimiento de los conocimientos sobre las plantas y los animales en Europa a fines del siglo XVWII refiere que Bakewell, el inventor de la ganadería capitalista, defendía la tesis del in breeding: cruzar los mejores especímenes, no solo al interior de una misma raza, sino al interior de una misma línea de descendencia e incluso al interior de una misma familia.

La palabra "híbrido", que literalmente significa "cruza", quedó asociada a la idea de agricultura moderna en virtud de los cambios en las técnicas de reproducción del maíz, operados a principios del siglo XX. Sin embargo, el dispositivo básico puesto en juego por la ingeniería del maíz es la autofecundación o purificación (Matchett, 2005). El mejoramiento moderno "supone administrar un proceso contradictorio: llevar al límite la purificación racial de ciertas plantas [endogamia] y simultáneamente conservar su capacidad de combinación para permitir la hibridación" (Arellano Hernández, 1999: 93)..10

Es decir, genetistas y los agricultores manipulan los vegetales, pero, mientras la selección casera dibuja una línea con movimiento, trazada a partir de los intercambios entre las familias y la interacción con las dinámicas ambientales, las líneas genéticas son conectores sin historia que vinculan seres cuya continuidad ha sido establecida de antemano (Ingold, 2013). La genealogía científica no sigue una trayectoria sino que reconstruye un plan. La línea abstracta del genetista es el fantasma del surco, a través del cual tanto los ingenieros como los agricultores controlan las cruzas. ${ }^{11}$

\section{LAS SIMIENTES DEL GÉNERO}

A fines de la década de 1980, la ONG que actúa en nuestra zona de estudio promovió el abastecimiento de semillas comerciales para huerta entre las familias del paraje. La distribución de insumos, cuyo acceso fue mediado por el dinero, cobró una importancia decisiva en la constitución de grupos de mujeres, articulando los espacios doméstico y público. ${ }^{12}$

Un trabajo sobre la circulación de semillas entre los pequeños productores de Misiones afirma que las semillas de huerta son de tipo comercial, mientras que las especies conservadas son las de maíz, poroto y zapallo, además de las ramas de mandioca y las mudas de batata (Vidal, 2010: 79).
11 | Las autofecundaciones científicas se controlan de manera mecánica: se siembran seis surcos de la línea pura que tendrá función femenina y dos surcos de la línea pura con función masculina. En el momento de la floración, las flores masculinas de la línea femenina son eliminadas y se dejan las flores masculinas de la línea masculina. La línea masculina es autofecundada y, en las plantas de la línea femenina, se forma un híbrido (Arellano Hernández, 1999).

10| El producto comercial o top cross es una cruza doble de híbridos simples engendrados por dos líneas puras

12 | La producción de alimentos a escala familiar se institucionaliza en Misiones a partir del año 1995, con la difusión de ferias de agricultores. Los ítems que se comercializan no coinciden con los del autoconsumo sino que se trata de producción de huerta, efectuada con semillas híbridas y en invernáculos. 
Es decir, las "semillas para huerta" mantienen con el autoconsumo una relación de exterioridad. ${ }^{13}$ Como señala una integrante y promotora de estos grupos: "Se quería sacar a la gente del poroto y del reviro. ${ }^{14}$ Enseñarles, porque se estaba perdiendo el autoconsumo. Tratamos que la huerta se haga cerca de la casa, que no se haga más en el rozado [espacio productivo principal]".

La administración de estas semillas estuvo en el origen de la cooperación entre mujeres, a través de la constitución de un fondo de crédito. De acuerdo al relato del técnico de la ONG: "[la actividad] Empezó a través de comprar las semillas, hicieron rifas, recaudaron fondos, se compraron las semillas en forma grupal y se entregaron a las socias. La que tenga plata hoy, puede pagar las semillas y la que no, se hace un registro, y después puede ir devolviendo de a poco, como pueda".

De este modo, en la localidad que estudiamos, mujeres de distintas generaciones, vinculadas por lazos de consanguinidad y afinidad (madres e hijas; suegras y nueras) se asociaron para llevar a cabo las huertas. El concepto de alimentación fue central en estos grupos, eclipsando la contraposición entre los sexos y consanguinizando los vínculos de afinidad. Cada nueva asociación se colocó en posición de "hija" con respecto a una "madre" patrocinadora. A nivel departamental, el grupo madre engendró ocho subgrupos, reuniendo un total aproximado de 120 mujeres. La distribución de semillas nutrió la creación de las asociaciones, consolidando los lazos engendrante-engendrado.

Como relatamos al inicio del artículo, una de las participantes desafió este englobamiento filial y constituyó por su cuenta una nueva organización. Censurada por las madres patrocinadoras, formó un "grupo particular", sin filiación con la casa matriz. Inició así una línea propia, a través de la cual se incorporó a colectivos institucionales más amplios (a la Asociación Civil de la Mujer de Rural y al Sindicato de Amas de Casa de la República Argentina).

La complementariedad entre los sexos caracterizó los inicios de la nueva asociación: "[Para reunir fondos] Hicimos riñas de gallos, las mujeres organizamos riñas de gallos con los hombres, acá!". ${ }^{5}$ Sin embargo, gradualmente, la exclusividad femenina se tornó hegemónica. Un censo de las necesidades de la mujer, realizado por las agencias gubernamentales en el año 2007, acentuó el carácter sexuado de la asociación. Refiriéndose al evento de entrega de los electrodomésticos, relevados por dicho registro, la presidente relata: "Los hombres acompañaron a las mujeres porque se iban a burlar de las mujeres. Hicimos una ronda y los hombres quedaron atrás. Cuando vieron que era verdad, que iban entregando una heladera para una, la batería de cocina para la otra, los hombres Iloraron junto con las mujeres!".

Posteriormente, la actividad de producción de huevos para la venta, puesta en marcha por la organización a través del vínculo con un programa de desarrollo, completó la exclusividad de género. El Estado subsidió la provisión de planteles de cien gallinas genéticamente modificadas (ponedoras), con alimentación especializada
13 | Los pequeños agricultores del estado de Río de Janeiro, estudiados por Carneiro (2008), consideran la producción de huerta como un "producto de afuera" (emplea semillas híbridas y pesticidas), contrapuesto a los "productos del rozado" provenientes de las sementes da terra (tubérculos de ñame, batata y mandioca)

14| Ambrossetti (1892) describe esta comida regional, característica del trabajador del monte, del siguiente modo: "Revirado: plato brasilero que se usa en viaje. Puede hacerse de cualquier carne frita o hervida que se pone en una bolsa llena de fariña" (1892:100).

15 | La riña de gallos es una actividad masculina; la reproducción de los especímenes se encuentra rigurosamente controlada en contraste con la liberalidad que domina los apareamientos de las gallinas comunes o criollas. 
y asistencia veterinaria, financiando, además, las instalaciones para segregar a las aves. De este modo, catorce gallineros o galpones de ponedoras se construyeron en la colonia.

Las combinaciones involuntarias, emanadas de la proximidad, marcan el carácter indiferenciado de la propagación doméstica. En contraposición, la segregación y el distanciamiento son reveladores de una intención de control y perpetuación de una identidad determinada. Los agricultores efectúan esta operación a propósito de una actividad no relacionada con los alimentos: la cría de gallos de riña. Un agricultor relata: "Las madres [de los gallos] también tienen que ser peleadoras, si veo que la gallina pelea cuando está suelta, ya la encierro para madre" (trabajo de campo, 2014).

A diferencia de la gallina común o criolla, propia del autoconsumo familiar, los especímenes genéticamente modificados del proyecto de desarrollo no encluecan. Los huevos deben ser incubados y es necesario efectuar una reposición de madres, perdiéndose el atributo autogenerativo de la cría doméstica.

El ciclo vital de las gallinas del programa está planificado y es descripto por la técnica estatal en los siguientes términos: "[las gallinas mejoradas] No necesitan gallo para poner huevos y no tienen pollitos. Sólo hembras en el gallinero. Ponen un huevo por día durante 18 meses y ahí se las descarta".

A través de esta actividad, las dirigentes de la organización impulsaron la consolidación de una línea de afiliación basada en el género, estableciendo una identificación entre la forma de reproducción de los animales y la organización de los humanos. De este modo, los hombres de la localidad sólo pudieron anexarse al emprendimiento a través de las mujeres, en calidad de marido o de hijo de una socia.

Sin embargo, una vez concluido el apoyo institucional, esta identificación se desvaneció y la actividad fue vuelta a familiarizar, perdiendo su connotación de género. Las gallinas ponedoras del programa tuvieron un destino semejante al de las criollas, ya que, según relatan las participantes: "Las largamos en el patio, con un gallo, para tener pollitos".

\section{LA PURIFICACIÓN CRIOLLA}

El segundo ejemplo de segmentación y refamiliarización que presentamos versa sobre las acciones de desarrollo, llevadas a cabo por la misma ONG que en 1980 había impulsado la provisión de semillas de huerta y la formación de grupos de mujeres. Así, en el año 2002, se puso en marcha en nuestra localidad de estudio una experiencia de rescate y mejoramiento de maíces criollos.

Como señalamos más arriba, los especímenes que componen la endoagricultura de los alimentos son producto de cruzas espontáneas, parcialmente estabilizadas por los propios agricultores. La denominación criollo se emplea para describir ese estado de cosas. 
Aplicado al maíz, este calificativo posee un escaso poder de discriminación, ya que lo propio de esta planta es el cruzamiento incesante (Arellano Hernández, 1999: 105).

En nuestra localidad de estudio, la intervención de la ONG se hizo necesaria porque "muy pocos productores mantenían cierta línea o razas de maíces con los que realizaban en forma empírica una selección todos los años" (INDES, 2008). La acción estuvo orientada a "purificar las semillas de los agricultores", rotulando las variedades y controlando la descendencia mediante la sistematización de los apareamientos.

Como comenta el técnico: "El maíz se cruza con mucha facilidad. Había que tomar las variedades de los productores y mejorarlas genéticamente, purificarlas".

La recuperación de las variedades implicó exacerbar la endogamia. Cada agricultor semillero se especializó en una sola clase, evitando la proximidad contaminante del maíz duro, un híbrido comercial de ciclo corto, difundido por las empresas tabacaleras.

Diversas estrategias de distanciamiento se pusieron en práctica con el fin de mantener la pureza, tales como la siembra posterior a la floración de los maíces plantados por los vecinos, la siembra de variedades diferentes en cuadros distantes y la utilización del monte como barrera de protección. Los maíces para harina (el maíz catete, por ejemplo) se dejaron de cultivar para que no se cruzaran con las variedades forrajeras, blanco principal del rescate de semillas nativas emprendido por la ONG.

El trabajo tecno-científico que se agregó para "pasar del grano a la semilla" introdujo rupturas con respecto a las prácticas habituales. ${ }^{16}$ La selección de las espigas, que antes se hacía con las mazorcas en el galpón, los técnicos les enseñaron a hacer en la misma planta. También incorporaron las mediciones de grano, chala y marlo y la estimación del rendimiento comenzó a efectuarse en kilos. ${ }^{17}$ De esta manera, se identificaron y catalogaron ocho variedades (Blanco duro, Leales 25, Caiano, Azteca o marlo sabugo fino, Matto Crosso, Central Mex, Dente cão y Chala roja).

El mejoramiento encarado por la ONG produjo varias segmentaciones. Entre los vegetales, la selección involucró exclusivamente a los maíces para forraje. ${ }^{18} \mathrm{Y}$, entre los humanos, el proyecto diferenció una línea de semilleristas, esto es, agricultores dedicados a la producción de semillas. A partir de 2006, la calificación semillero se volvió corriente en la zona.

Quienes devinieron semilleristas fueron mayoritariamente los hombres. Las mujeres pertenecientes a los grupos de desarrollo acompañaron la actividad prestando su apoyo..$^{19}$ El conjunto se aglutinó en torno a una cooperativa agropecuaria y forestal ${ }^{20}$, vinculada a la ONG y presidida por el marido de una de las patrocinadoras de los grupos de mujeres. En hibridación con las acciones de desarrollo, ese agrupamiento se consolidó como una casa, anexándose las hijas de otras familias vinculadas a la organización, ya que dos de los hijos de la pareja contrajeron matrimonio con hijas de socias de los grupos de mujeres. El hijo mayor sucedió al padre en la dirección de la cooperativa, mientras su esposa se convirtió en administradora del proyecto semillero. A su vez, el hermano menor y su mujer
16 | Colaboró en la investigación el ingeniero agrónomo Julián Cámara Hernández, profesor consultor de la Facultad de Agronomía de la Universidad de Buenos Aires.

17| El maíz es un cultivo de uso doméstico que se estima en "manos de maíz". Una mano comprende 50 espigas en el nordeste de Brasil y 64 espigas en Río Grande do Sul (una mano consta de 16 atadosy cada atado tiene 4 espigas). En el nordeste de Misiones se considera que una mano comprende 64 espigas y pesa aproximadamente $12 \mathrm{~kg}$.

18 | La población de maíces nativos en la provincia está diferenciada en dos grupo principales: los harinosos, empleados para alimentación humana y conservados por las comunidades mbya guaraní, y los dentados utilizados por los pequeños productores para la alimentación animal. Cámara Hernández y Miante Alzogaray (2011) identifican quince razas nativas de maíz en la provincia de Misiones, diferenciadas entre sí por atributos de planta, panoja, espiga, granos y longitud del período reproductivo. Son las siguientes: "Amarillo Ancho", "Amarillo Angosto", "Blanco Ancho", "Blanco Angosto", "Variegado", "Overo", "Rosado", "Colorado". "Pororo ó Chico". "Pororo ó Crande", "Pipoca Amarillo", "Pipoca Colorado", "Azul", "Tupi í Blanco" y "Tupi í Amarillo".

19| De los 27 semilleristas que participan en el proyecto de mejoramiento llevado a cabo por la ONG sólo dos son mujeres.

$\mathbf{2 0 |}$ La cooperativa era yerbatera en su origen y proporcionó la estructura para la comercialización de las semillas, ya que se trataba de las mismas familias.

Cuenta con 86 socios activos. 
quedaron a cargo del local de venta de los productos de la cooperativa (semillas y alimento balanceado). ${ }^{21}$

Al definir líneas o razas criollas, el programa de mejoramiento de la ONG convirtió el parentesco en un asunto público, haciendo visibles y estratégicos los matrimonios. ${ }^{22} \mathrm{~A}$ través de la alianza, los agricultores semilleros contribuyeron a establecer la exclusividad de una línea o casa, aglutinada en torno a la cooperativa.

La segmentación de la fluidez de los apareamientos entre maíces, y su necesaria planificación, fue correlativa de la relevancia que cobraron las relaciones de afinidad en la segregación de los humanos.

A semejanza de lo descripto en el ejemplo anterior, la apropiación familiar del colectivo institucional fue desafiada por los agricultores excluidos de la línea de semilleristas, que constituyeron un agrupamiento alternativo, considerando que "la cooperativa es limitada"; "es de los parientes de H."; "es sólo para los que ya son socios".

Mayoritariamente ocupantes de tierras privadas, los productores marginados habían experimentado una división interna en ocasión de la regularización de la tenencia. Una fracción de los ocupantes había llevado a cabo convenios amistosos con el propietario, mientras que el resto formó una organización de lucha, logrando — con apoyo estatal - la expropiación del predio y la concesión de un patrimonio valioso: una plantación de 27 hectáreas de yerba mate, existente sobre la tierra (Schiavoni, 2008; 2017). Fue este segundo grupo el que constituyó una nueva cooperativa, excluyendo a aquellos ocupantes que habían celebrado los convenios con el propietario, eludiendo también de ese modo un reclutamiento basado en el parentesco, ya que los hijos de los líderes de los grupos enfrentados habían quedado vinculados a posteriori por una alianza.

La disputa suscitada a propósito de la nueva cooperativa fue vuelta a familiarizar, planteándose en términos de un conflicto entre consuegros. Uno de los contrincantes amenazó con "devolverle la hija" al consuegro opositor, recriminándole el haberse asociado con "gente de afuera", olvidando a sus parientes. El acusado justificó la exogamia afirmando que "santo de la casa no hace milagros".

La extrema gravedad del incidente, de acuerdo a los relatos locales, radicó en que "hizo público lo familiar".

Este cambio de registro de lo doméstico, que torna visible aquello que funciona para ser mantenido oculto, es lo que Strathern (2009) denomina el parentesco transformado: "el parentesco deja de ser tomado como dado. Las relaciones de parentesco pasan a ser materia de transacciones, y las personas se dedican a expandirlas de la única manera posible — produciendo 'más' parentesco" (Strathern, 2009: 386).

Las asociaciones tabacaleras de la zona ofrecen evidencias adicionales de la transformación del parentesco. El intenso faccionalismo que caracteriza la vida de estas organizaciones hizo que la alianza matrimonial entre los hijos de dos dirigentes apareciera como una garantía de lealtad. Así, el presidente de la asociación principal

21 | La comercialización de semillas implicó el registro en el INASE [Instituto Nacional de Semillas], planteando el problema de la propiedad. Los técnicos sostuvieron que "las semillas criollas no son de la cooperativa, no son nuestras, son de todos" $y$ gestionaron la categoría de identificadores de semillas, que les permite comercializar hasta 80.000 kg por año. Las semillas purificadas se comercializan fuera de la comunidad local y el principal comprador es el Estado.

22 | La relevancia económica que va adquiriendo el parentesco en la localidad es perceptible en los comentarios casuales, proferidos por los vecinos. Así, hemos escuchados afirmaciones del tipo: "Don K. es semillero. Como su yerno está en ONG, ingresó al programa". En otro caso: "La cooperativa es una puerta cerrada. A Negro le compran las semillas de poroto sable porque la hermana trabaja ahí". 
- luego de permanecer diez años en el cargo y ser expulsado por un antiguo colaborador - , fundó un agrupamiento alternativo y saludó con beneplácito el enlace matrimonial de su hijo con la hija del vicepresidente de la nueva asociación. En la localidad, el hecho fue comentado favorablemente, mediante la afirmación: "Queda todo en familia". Sin embargo, en una elección posterior, los consuegros compitieron en listas opuestas, y el que resultó perdedor (el padre de la muchacha) expulsó de su tierra al yerno.

De este modo, en un contexto general de activación de lazos indiferenciados, la afinidad deviene una vía a través de la cual lo familiar se transforma en un asunto público y pasa a ser objeto de estrategias de selección.

\section{CONCLUSIONES}

Nuestro trabajo versa sobre las relaciones entre los humanos y los vegetales y animales alimenticios, en el marco de acciones de desarrollo tendientes a modernizar la pequeña agricultura no indígena del Nordeste argentino.

A diferencia de las homologías abstractas planteadas por el totemismo, en el caso que analizamos, la asociación interespecie está arraigada en un modo determinado de propagación, común a humanos, animales y vegetales.

Así, nuestros datos no contienen enunciados nativos que expresen paralelismos directos entre los humanos y las plantas o animales sino que la analogía descansa en un formato de acción. Hemos enfocado la atención hacia el registro material de las formas de propagación con el fin de documentar un modo de relacionamiento interespecie, que conceptualizamos como un lazo general de contigüidad, que asocie sin el recurso a un diseño expresado verbalmente y que dirija las combinaciones.

De esta manera, los vínculos de proximidad y semejanza que operan en la multiplicación de las variedades criollas de la alimentación familiar son activados también en los procesos de emparentamiento que están en la base de las prácticas matrimoniales de las familias que integran las comunidades rurales de la frontera agraria de Misiones.

Orientadas a purificar los especímenes surgidos de las mezclas no planificadas de la domesticación casera, las acciones de desarrollo que examinamos intentaron sustituir la contigüidad analógica, que engendra tipos fluctuantes, por un formato de acción tendiente a replicar variedades estabilizadas de vegetales, animales y humanos.

Al operar mediante intercambios de tipo contractual, los agenciamientos institucionales del desarrollo pusieron de manifiesto las relaciones como conexiones explícitas. La marca de alteridad fue proporcionada por la alianza.

El recurso a la noción de casa nos permitió enfocar el parentesco de manera menos determinista, contemplando los efectos de los objetos técnicos del desarrollo 
sobre las dinámicas familiares, a través de procesos simultáneos de extranjerización de próximos y de alineación de semejantes. Del mismo modo que los agricultores se vieron obligados a distanciar sus rozados para purificar un maíz que había sido emparejado por los apareamientos espontáneos, la institucionalidad del desarrollo segmentó la consanguinización de los lazos, constitutiva de la trama local de humanos, recortando socios y contrapartes.

La operación, sin embargo, no se tornó hegemónica y los colectivos técnicos se mantuvieron en fricción con los agenciamientos anteriores, en el marco de un proceso más amplio de individuación por familiarización.

Gabriela Schiavoni es Antropóloga. Investigadora del CONICET y Profesora del Programa de Posgrado en Antropología Social de la Universidad Nacional de Misiones.

FINANCIACIÓN: Conicet y Universidad Nacional de Misiones.

CONTRIBUCIÓN DE AUTORÍA: Es autora de numerosos artículos y libros sobre antropología y desarrollo en la frontera agraria de Misiones. Actualmente trabaja sobre agriculturas guaraníes, colonas y agroecológicas. Entre sus contribuciones podemos mencionar: Colonos y Ocupantes; Campesinos y Agricultores Familiares; "Fabricando el homo economicus. Dispositivos cognitivos en un programa de crédito"; "La transacción de los alimentos domésticos. El régimen de familiaridad como forma de coordinación económica".

\section{REFERENCIAS BIBLIOCRÁFICAS}

ARELLANO HERNANDEZ, Antonio. 1999. La producción social de los objetos técnicos agrícolas: antropología de la hibridación del maízy de los agricultores de los valles Altos de México. México, Ed. Universidad Autónoma del Estado de México.

BENVENISTE, Emile. [1969] 1994. Le vocabulaire des institutions indoeuropéennes. Paris, Ed. De Minuit.

BERTONI, Moisés. 1900. "Resumen del cultivo y beneficio de la mandioca".
Revista de Agronomía y Ciencias Aplicadas, Asunción, tomo 2, n. 5-6: 209-224.

BERTONI, Moisés. 1927. Agenda y Mentor Agrícola. Guía del agricultor \& colono. Puerto Bertoni, Ediciones Ex Sylvis.

BOLTANSKI, Luc. [1990] 2000. El amor y la justicia como competencias. Tres ensayos de sociología de la acción. Buenos Aires, Amorrortu.

BOLTANSKI, Luc. 2009. De la Critique. Précis de sociologie de l'emancipation. Paris, Gallimard. 
ARTículo | Gabriela Schiavoni | Consanguinizary Afinizar. La domesticación de los animales,

BOURDIEU, Pierre. 2002. Le bal

des célibataires. Crise de la société

paysanne en Béarn. Paris, Seuil.

CABRAL DE OLIVEIRA, Joana. 2008. "Social Networks and Cultivated Plants: Exchange of Planting Material and Knowledge". Tipití: Journal of the Society for the anthropology of Lowland South America, $6^{\circ}$ (1-2): 101-110.

CÁMARA HERNÁNDEZ, Julián y MIANTE ALZOGARAY, Ana. 2011. "Razas de maíz nativas de Misiones". Boletín de la Sociedad Argentina de Botánica, 46 (Supl.): p. 231.

CARNEIRO DA CUNHA, Manuela. 2012. "Questões suscitadas pelo conhecimento tradicional”. Revista de Antropologia, São Paulo, 55(1): 439-464.

CARNEIRO, María José. 2008. "De "produtor" a "consumidor": mudanças sociais e hábitos alimentares". In: PESSANHA NEVES, D. (org.), Processos de constituiçãoe reprodução do campesinato no Brasil. Formas dirigidas de constituiçao do campesinato. São Paulo, Ed. UNESP, pp. 151-171.

\section{CARSTEN Janet y HUGH-JONES}

Stephen. 1995. "Introduction". In: CARSTEN ]. y HUGH-JONES S. (eds.), About the house. Lévi-Strauss and beyond. Cambridge University Press, pp. 1-35.

CHAUMEIL, Bonnie y CHAUMEIL, JeanPierre. 1992. "'́oncle et le neveu. La parenté du vivant chez les Yagua (Amazonie péruvienne)". Journal de la Société des Américanistes, tome 78, n. 2, pp. 25-37.

DELÊTRE Marc, McKEY Doyle B. y HODKINSON Trevor R. 2011. "Marriage exchanges, seed exchanges, and the dynamics of manioc diversity", PNAS [Proceedings of the National Academy of Sciences of the United States of America], 108 (45): pp. 18249-18254.
DESCOLA, Philippe. 2012. Más allá de naturaleza y cultura. Buenos Aires, Amorrortu.

DICARD, Jean Pierre. 2009. L'Homme et les animaux domestiques. Anthropologie d'une passion. Fayard, Millau.

EMPERAIRE, Laure. 2010. Dossiê de registro do Sistema Agrícola Tradicional do Rio Negro. Brasília, ACIMRN/IPHAN/IRD/Unicamp/CNPq

FEIL, Daryl. 1978. "'Straightening the Way': An Enga Kinship Conundrum". Man, vol. 13, n. 3: 380-401.

FOX, James. 1971. "Sister's child as plant. Metaphors in an Idiom of Consanguinity". In: NEEDHAM R. (ed.). Rethinking marriage and kinship. Londres, Routledge, pp. 219-243.

GALLERO, Cecilia. 2008. El llamado del oro verde. Memorias de inmigrantes suizos en Misiones. Buenos Aires, Araucaria Editora.

GODELIER, Maurice. 2013. Lévi-Strauss. Paris, Les éditions du Seuil.

HATT, Gudmut. 1951. "The Corn Mother in America and in Indonesia". Anthropos, 46: pp. 853-914.

HAUDRICOURT, André-Ceorges. 1962. "Domestication des animaux, culture des plantes et traitement d'autrui". L' Homme, tome 2, n. 1: pp. 40-50.

HAUDRICOURT, André-Georges. 1964. "Nature et culture dans la civilisation de l'igname: l'origine des clons et des clans". L'Homme, tome 4, n. 1: pp. 93-104.

HIATT, Lester. 1969. "Totemism tomorrow: The future of an Illusion”. Mankind, 7: pp.83-93.

INGOLD, Tim. 2013. Une brève histoire des lignes. Paris, Zones Sensibles. 
ARTículo | Gabriela Schiavoni | Consanguinizary Afinizar. La domesticación de los animales,

LÉVI-STRAUSS, Claude. [1962] 1963.

La pensée sauvage. Paris, Plon.

LÉVI-STRAUSS, Claude. [1967] 1971.

De la miel a las cenizas. México,

Fondo de Cultura Económica.

LEVI-STRAUSS, Claude. 1984.

Paroles données. Paris, Plon.

MAIZZA, Fabiana. 2014. "Sobre a criançasplanta: o cuidar e o seduzir no parentesco jarawara". Mana, 20 (3): 491-518.

MARTÍNEZ CROVETTO, Raúl. 1968. "Notas sobre la agricultura de los indios guaraníes de Misiones (República Argentina)". Actas y Memorias, $37^{\circ}$ Congreso Internacional de Americanistas. Buenos Aires.

MATCHETT, Karin. 2005. "Debates sobre el método de maíz híbrido en Estados Unidos y su traducción en México". In: ARELLANO HERNÁNDEZ, A. KREIMER, P. OCAMPO LEDESMA y ]. VESSURI, H. (comps.). Ciencias agrícolas y cultura científica en América Latina. Buenos Aires, Prometeo libros, pp.79-89.

MEILLASSOUX, Claude. [1975] 1978. Mujeres, graneros y capitales. México, Ed. Siglo XXI.

MORIM DE LIMA, Ana Gabriela. 2017. "A cultura da batata-doce: cultivo, parentesco e ritual entre los krahô". Mana, 23 (2): 455-490.

POCHETTINO, Leila. 2007. "La dinámica en la horticultura en comunidades Mbya-Guaraní, Misiones, Argentina". Etnobiología, 5 (36-50), pp.36-50.

RACINE, Luc. 1989. "Du Modèle analogique dans l'analyse des représentations magicoreligieuses". L'Homme, tome 29, n. 109: 5-25.

RACINE, Luc. 1986. "La terre-mère et les mères végétales en Océanie et en
Asie du Sud-est: symbolisme et analogie". L'Ethnographie, tome 82, n. 98-99: 27-50.

RIVAL, Laura. 2001. "Seed and Clone: The symbolic and social significance of bitter manioc cultivation". In: RIVAL, L. y WHITEHEAD, N.(eds.), Beyond the visible and the material. The americanization of society in the work of Peter Rivière. Oxford, University Press, pp. 57-79.

SAGyPA-PROINDER. 2004. Catálogo de tecnologías para pequeños productores agropecuarios, Secretaría de Agricultura, Ganadería y Pesca de la Nación Argentina.

SCHIAVONI, Gabriela. 2005. "'Hacerse parientes' Estrategias de alianza y reproducción social de los ocupantes agrícolas en el NE de Misiones (Arg.)". Anuário Antropológico, v.30: 95-118.

SCHIAVONI, Gabriela. 2008. "Madereros y Agricultores. La constitución de un mercado de tierras en el nordeste de Misiones". In SCHIAVONI G. (comp.), Campesinos y agricultores familiares. La cuestión agraria en Misiones a fines del siglo XX. Buenos Aires, Ed. Ciccus, pp. 74-84.

SCHIAVONI, Gabriela. 2017. "Colonización y ocupación no planificada. La mercantilización de la tierra agrícola en Misiones (19202000)". Travesía, 19 (1): 77-106.

STAMPELLA, Pablo César. 2015. Historia local de naranja amarga (Citrus x aurantium L., Rutaceae) del Viejo Mundo asilvestrada en el corredor de las antiguas misiones jesuíticas de la provincia de Misiones (Argentina). Caracterización desde una perspectiva interdisciplinaria. La Plata, Tesis de Doctorado, Universidad Nacional de La Plata.

STRATHERN, Marilyn. [1988] 2009. O gênero da dádiva. Problemas com as mulheres e problemas com a sociedade na Melanesia. Campinas, Ed. Unicamp.

TAYLOR, Anne Christine. 2000. "Le sexe de la proie. Représentations jivaro du lien de parenté". L' Homme, n. 154-155: 309-334. 
ARTículo | Gabriela Schiavoni | Consanguinizary Afinizar. La domesticación de los animales,

VIDAL, Violeta. 2010. Una aproximación al movimiento por la semilla campesina en Misiones. Posadas, Tesis de Licenciatura, Universidad Nacional de Misiones.

VIVEIROS DE CASTRO, Eduardo. 2008. "The Gift and the Given: Three Nano-Essays on Kinship and Magic". In: BAMFORD, S. y LEACH, J. (org.), Kinship and Beyond: the genealogical model reconsidered.

Oxford, Berghahn Books, pp. 237-268.

WAGNER, Roy. 1977. "Analogic

kinship: a Daribi example". American

Ethnologist, 4 (4), pp. 623-642.

WOORTMANN, Ellen. 1995. Herdeiros, parentes e compadres. Colonos do Sul e sitiantes do Nordeste. São Paulo-Brasília, Hucitec.
YSSOURIBEHERE, Pedro. 1904. Investigación agrícola en el territorio de Misiones. Anales del Ministerio de Agricultura tomo I, n. 9, Buenos Aires, Compañía SudAmericana de Billetes de Banco.

\section{MATERIALES CONSULTADOS}

Asociación de Plantadores de Tabaco de Misiones. 1999. Revista La voz del tabacalero, n. 16.

INDES [Instituto de Desarrollo Social y Promoción Humana]. 2008. "Registro de Experiencias, Rescate, Identificación y Mejoramiento de Variedades de Maíces Locales".

INTA [Instituto Nacional de Tecnología Agropecuaria]. 2008. "Producción de Mandioca y sus usos". Montecarlo, Misiones.

Recibido el 31 de agosto de 2017. Aceptado el 2 de septiembre de 2020. 